\title{
Homens de pedra? Pesquisando o processo de trabalho e saúde na extração e no beneficiamento do mármore - relato de uma experiência
}

\author{
Maria das Graças Barbosa Moulin ${ }^{25}$, \\ Cleilson Teobaldo dos Reis e Grace Hitomi Wenichi ${ }^{26}$
}

\begin{abstract}
A extração e beneficiamento de mármore constitui importante atividade econômica do Estado do Espírito Santo. Estudos apontam as péssimas condições em que este trabalho se realiza, acarretando elevado número de acidentes e constantes agravos à saúde. Além das condições de trabalho, objetivamos conhecer a organização do trabalho para avaliar os efeitos produzidos na subjetividade dos trabalhadores. A pesquisa baseou-se nas estratégias metodológicas da Ergonomia Situada e Psicodinâmica do Trabalho. Utilizamos como instrumentos de coleta de dados a observação participante, entrevistas individuais e coletivas com trabalhadores. Utilizamos a análise do discurso para aproximarmo-nos dos sentidos atribuídos às noções de trabalho, saúde e sua interface. Entendemos a saúde enquanto um processo e o trabalho enquanto fato social importante para a saúde e a subjetividade dos trabalhadores. Para os trabalhadores, a saúde era condição mesma de trabalho, pois ter saúde é ter um corpo apto para trabalhar. O caráter insidioso das doenças ocupacionais não os impedia de realizar suas tarefas. A preocupação com a saúde era projetada para um futuro incerto, quando a doença já estivesse instalada, impedindo-os de trabalhar. Esta noção permitia aos trabalhadores suportar um cotidiano penoso de trabalho, mas dificultava ações mais efetivas de prevenção à saúde e segurança no trabalho.

Palavras-chave: trabalho, mármore, granito, saúde, subjetividade.
\end{abstract}

\section{Introdução}

$\mathrm{M}$ oramos num estado - Espírito Santo - cuja grande parte da economia está alicerçada prioritariamente no setor de rochas ornamentais: mármore e granito. No sul do estado, na região de Cachoeiro do Itapemirim, encontra-se a maior parte da produção.

Desta região, ouvimos com freqüência notícias de acidentes fatais, mulheres que ficaram sem seus maridos e filhos ou de homens que ficaram sem suas pernas ou braços na luta pela sobrevivência através da extração, beneficiamento e transporte de mármore.

Aqui, da cidade de Vitória (capital do Estado), preocupados que estávamos nas questões relativas à Saúde e Trabalho, imaginávamos o calor, o mal-estar, o trabalho bruto, homens rudes, patrões insensíveis, enfim, o sofrimento.

Esse quadro, que nos faz imaginar o trabalho na idade das pedras, era tudo que sabíamos a respeito do setor do mármore e granito. Poucos estudos foram realizados no setor, raros os que objetivavam o estudo da saúde. Parecia-nos urgente pesquisar a relação entre trabalho, saúde e subjetividade junto àquela categoria de trabalhadores. Como eles

\footnotetext{
25 Professora do Departamento de Psicologia Social e do Desenvolvimento da Universidade Federal do Espírito Santo. Psicóloga e mestre em psicossociologia.

${ }^{26}$ Graduandos em psicologia pela Universidade Federal do Espírito Santo.
} 
suportavam esta realidade? Como e porque voltavam ao trabalho no dia seguinte? Eram estas as nossas questões.

\section{O contexto atual do mundo do trabalho}

Pesquisar trabalho e saúde em qualquer setor da economia nos obriga a contextualizá-lo do ponto de vista social, político e econômico, onde podemos visualizar as pressões a que estão submetidos os trabalhadores.

O atual modelo de produção capitalista caracterizado, entre outras coisas, pela introdução de novas tecnologias e automação no processo produtivo, vem provocando transformações no mundo do trabalho que se fazem sentir não só nos aspectos técnicos e organizacionais no interior das empresas, como também, e ao mesmo tempo, vem produzindo novos conceitos e paradigmas que justificam e legitimam tais transformações.

Qualidade total, just in time, produtividade, flexibilização, competitividade são alguns dos termos que passaram a compor o discurso que norteia o mundo do trabalho e que, alicerçados nos discursos e práticas da política neoliberal, vêm gerando efeitos sociais graves mais notadamente, o desemprego estrutural e o enfraquecimento do movimento sindical - o que intensifica as já precárias condições de trabalho daqueles que conseguem se manter em seus postos de trabalho.

Tomando-se por referência esse quadro, pode-se verificar, entretanto, que essas transformações não se realizam de forma homogênea. Tal como aponta Antunes (1997):

(...) transformações, presentes ou em curso, em maior ou menor escala, dependendo de inúmeras condições econômicas, sociais, políticas, culturais, etc., dos diversos países onde são vivenciadas, penetram fundo no operariado industrial tradicional, acarretando metamorfoses na forma de ser do trabalho (p. 72).

A complexidade do mundo do trabalho atual comporta métodos e procedimentos do tipo taylorista, toyotista e até mesmo processos produtivos ainda mais arcaicos, perigosos e menos sistematizados, convivendo lado a lado, por vezes, até mesmo numa mesma empresa.

Essa realidade de trabalho complexa e heterogênea pode ser verificada no setor de extração e beneficiamento de mármore e de granito. É, sem dúvida, a principal opção de inserção no mercado de trabalho que a população trabalhadora dessa localidade possui.

No entanto, apesar da beleza das peças de mármore e da contribuição do setor à economia do estado e nacional, o processo de trabalho é considerado perigoso, insalubre e penoso, ou seja, a precariedade nas condições e execução do trabalho antecede a chamada Terceira Revolução Industrial e, como efeito desta, provavelmente se agrava.

\section{Trabalho e saúde}

Alguns estudos sobre trabalho e saúde realizados nesse setor revelam que a incidência de doenças ocupacionais e acidentes, muitos envolvendo mutilações e morte, estão diretamente relacionados às péssimas condições de trabalho que acabam por submeter a população de trabalhadores a um tipo de serviço penoso e insalubre. 
Tais estudos concentraram suas investigações, principalmente, nas condições de trabalho - aqui entendidas, segundo Dejours, Abdoucheli e Jayet (1994) como pressões físicas, mecânicas, químicas e biológicas do posto de trabalho e que têm por alvo principal o corpo dos trabalhadores, podendo ocasionar desgaste, envelhecimento e doenças somáticas, evidenciando-se, dessa forma, o meio-ambiente como fonte de doenças e agravos à saúde física.

Se, por um lado, as condições de trabalho operam do ponto de vista físico, segundo esses mesmos autores, a organização do trabalho atua ao nível do funcionamento psíquico. Entende-se organização de trabalho como divisão de trabalho: divisão de tarefas entre os trabalhadores, repartição, cadência e enfim, o modo operatório prescrito; e a divisão de homens: repartição de responsabilidades, hierarquia, comando, controle etc.

Neste sentido, é possível conhecer não só os efeitos das condições de trabalho sobre a saúde física, mas também investigar e conhecer como as pressões decorrentes da organização do trabalho atuam sobre a saúde mental e a subjetividade dos trabalhadores.

Entendendo-se a atividade profissional não só como um modo de subsistência, mas também como uma forma de inserção social, onde aspectos físicos e psíquicos são mobilizados, os estudos já produzidos referentes à relação entre o trabalho e a saúde mental passam a se configurar como importantes instrumentos de análise que nos permitem identificar quais as condições em que o trabalho pode estar funcionando como uma fonte de sofrimento e deterioração da saúde ou como um fator de equilíbrio e de desenvolvimento e bem-estar. Tal como aponta Dejours (1993), "A questão que nos é colocada pela psicopatologia do trabalho não é a disjuntiva: 'Trabalho ou não-trabalho?', mas antes, 'Qual trabalho?"' ( p. 102).

Para responder a essa questão, faz-se necessário entender o trabalho não só nos seus aspectos objetivos e quantitativos, que tentam dizer da relação homem-trabalho, mas também evidenciar o seu caráter de "operador fundamental na própria construção do sujeito" (Dejours et al., 1994, p. 143) ou como "(...) um espaço da construção do sentido e, portanto, de conquista da identidade, da continuidade e historicização do sujeito” (p. 143).

Segundo os mesmos autores, o sofrimento, concebido enquanto uma vivência subjetiva, pode desencadear dois processos distintos, a saber: a construção de estratégias defensivas, constituindo-se como uma modalidade de adaptação às pressões de uma organização do trabalho; e a inteligência astuciosa, esta entendida enquanto processos psíquicos mobilizados pelo sujeito na tentativa de subverter a organização oficial do trabalho, utilizando-se de procedimentos mais eficazes que os modos operatórios prescritos.

Dejours et al. (1994) chega a distinguir dois tipos de sofrimento: o sofrimento criador e o sofrimento patogênico. O último aparece quando todas as margens de liberdade na transformação, gestão e aperfeiçoamento da organização do trabalho já foram exploradas e o sofrimento passa a gerar efeitos sobre o aparelho mental e o equilíbrio psíquico do sujeito, o que pode desembocar em distúrbios mentais ou psicossomáticos ou mesmo em doenças. Por outro lado, nas palavras do autor:

Quando o sofrimento pode ser transformado em criatividade, ele traz uma contribuição que beneficia a identidade. Ele aumenta a resistência do sujeito ao risco de desestabilização psíquica e somática. $\mathrm{O}$ trabalho funciona então como um mediador para a saúde. (p. 137)

Se o trabalho se reveste de importância fundamental na própria constituição do sujeito, parece-nos que conhecer as condições em que ele se dá e sua organização constitui-se em um instrumento fundamental para análise e investigação dos efeitos que essa atividade produz sobre o indivíduo. 
Estávamos interessados tanto nas condições quanto na organização do trabalho, na prescrição e no trabalho realmente executado pelos trabalhadores, nos "jeitinhos", na utilização do maquinário e dos equipamentos de segurança, nas artimanhas promovidas coletivamente para dar conta do perigo de "pedras voadoras", de ruídos ensurdecedores e, por fim, retornar no dia seguinte.

\section{A vivência dos pesquisadores}

Importante ressaltar a valorização da intersubjetividade enquanto possibilidade de acesso ao sentido que aqueles trabalhadores atribuíam à sua realidade de trabalho e a vivência que tivemos ao realizar nosso trabalho de campo. Em meio a poeira, estradas perigosas, caminhões velhos aparentando fragilidade, temíamos: e se um caminhão desses despencar? E se o nosso próprio carro despencar? Será que chegamos em horário de "fogo"? Não, disse um. Sim, disse outro. E lá íamos correndo, a adrenalina a todo vapor. Será que voltaríamos no próximo mês? Trabalhadores simpáticos, dando tchau... Que nada! Estavam tentando avisar que a aluna estava em local de explosão. Os trabalhadores faltaram à reunião, será que não foram avisados? Não, estão escondidos, porque vão "dar fogo" agora! Meu Deus! E eu faço o quê? Corro de costas, rezo, me jogo no chão, maldita hora em que meti neste projeto maluco.

Deparamo-nos com o perigo de sermos atingidos por pedras no momento de explosões nas empresas de extração e com agravos à saúde dos próprios alunos pesquisadores (rinites alérgicas, insolação, transtornos gastrointestinais etc.). Para além disso, a cada tarde que voltávamos do campo, o sentimento era generalizado - extremo cansaço: pela dificuldade de ouvir os trabalhadores (devido ao ruído), o cabelo endurecido de tanto pó, o rosto queimado (apesar do protetor solar). Os bonés pouco protegiam porque o sol refletido nas pedras brancas queimava de baixo para cima também. Tudo doía: as pernas, a garganta, a cabeça, os olhos. A partir dessas experiências, nossas questões se tornavam mais e mais urgentes de serem respondidas: como esses trabalhadores agüentam? (nós mal nos agüentávamos!) Como e por que eles retornam no dia seguinte? (tínhamos vontade de sumir!).

Este modo de produção de conhecimento fala de uma ética de ensino e pesquisa no campo do trabalho e saúde que é pensada e realizada a partir do discurso do próprio trabalhador. Esta forma de proceder nos ensina: estar no lugar onde o trabalhador executa seu trabalho, ouvir dele a explicação sobre o processo de trabalho, comparar a vivência do trabalhador com as nossas, as perplexidades face àquilo que sentíamos e vivíamos ali. Este é um ponto fundamental no trabalho que realizamos no setor de mármore em Cachoeiro. Deixamos claro aos trabalhadores que não detínhamos o conhecimento de sua realidade de trabalho e podemos dizer que aprendemos muito com aqueles trabalhadores. Não apenas sobre a realidade de seu trabalho e de suas vidas, como também pudemos repensar nossas vidas a partir desta vivência de pesquisa. Nosso trabalho consistiu em ouvir, discutir, rediscutir.

\section{Metodologia}

Como já referido, a pesquisa se desenvolveu junto às empresas ligadas às atividades de extração e beneficiamento de mármore e granito, na cidade de Cachoeiro de Itapemirim. A escolha do local aconteceu em função da grande concentração de empresas nesta 
localidade, assim como pela possibilidade de ter acesso a comunidades inteiras que vivem quase que exclusivamente em torno dessa atividade econômica.

Tratou-se de um estudo exploratório e consideramos, além das condições, também a organização do trabalho. Nesse sentido, foi possível conhecer não só os efeitos das condições de trabalho sobre a saúde física, mas também investigar e conhecer como as pressões decorrentes da organização do trabalho atuavam sobre a saúde mental e a subjetividade dos trabalhadores.

Procuramos compreender o sentido que os trabalhadores atribuíam à atividade que realizavam cotidianamente, pois somente desta forma evidenciaríamos a dominação e também as formas de resistência e luta que os trabalhadores constróem - e que podem proteger ou agravar sua saúde.

Interessou-nos aqui o dado qualitativo, muito mais do que o quantitativo - não há possibilidade de acesso à vida cotidiana, ao sentido que os trabalhadores atribuem às suas atividades, senão por meio da intersubjetividade. Somente desta forma poderíamos aprofundar as questões sobre saúde e trabalho que abordamos junto aos trabalhadores.

Para tanto, embasamo-nos nas referências metodológicas sugeridas pela Ergonomia Situada, que nos possibilita conhecer e analisar o trabalho real - em detrimento do trabalho prescrito pela gerência - ou seja, a análise do trabalho através da observação nos locais onde ele se realiza. Tivemos a oportunidade de observar (e de alguma forma, sentir) in loco as cargas físicas, psíquicas e cognitivas a que os trabalhadores estão submetidos, considerando ainda a variabilidade inter e intra-individuais.

Referenciamo-nos ainda na Psicodinâmica do Trabalho, cuja metodologia nos permitiu conhecer, através de entrevistas coletivas e individuais, a vivência subjetiva dos trabalhadores frente às suas atividades cotidianas. Os discursos e comentários suscitados nesses encontros possibilitaram-nos investigar quais os processos psíquicos mobilizados e coletivamente construídos pelos sujeitos para se manterem na "normalidade" frente a uma situação de trabalho penosa, insalubre e perigosa.

Nas primeiras empresas visitadas foram realizadas apenas observação participante que, segundo Becker (1997), consiste em observar as pessoas e situações a que se está estudando, entabular conversas a fim de ter acesso às interpretações que elas têm dos acontecimentos que se observa.

Importante ressaltar as diversas dificuldades que fomos encontrando no decorrer da abordagem ao campo. A possibilidade ou não de superá-las é que norteou, de certa maneira, nossa estratégia metodológica em campo.

A distância entre as empresas visitadas era um obstáculo, além da própria dificuldade de acesso a algumas delas devido à precariedade das vias de acesso, que consistiam em estradas de chão estreitas com trabalhadores quebrando pedras (marruadas) no meio do caminho. Caminhões subindo e descendo com grandes blocos de mármore. Em outras empresas (como a de moagem, por exemplo) a produção era contínua, o que dificultava o contato com os trabalhadores. Em algumas empresas fomos recebidos com respeito; em outras fomos encorajados a nos retirar; e em algumas fomos recebidos gentilmente, mas para uma visita apenas, sem possibilidade de continuação do trabalho de campo da pesquisa.

Devido às dificuldades encontradas nas atividades em campo acima descritas, a partir da quinta abordagem ao campo, entendemos que para a finalidade de nossa pesquisa - estudo exploratório de natureza qualitativa - as questões até então suscitadas nos encontros anteriores seriam melhor aprofundadas se limitássemos nossas visitas a três empresas que contemplariam a diversidade das atividades que compõem o setor, quais sejam: empresa de extração com 22 trabalhadores, empresa de beneficiamento com 20 trabalhadores e empresa de moagem com 60 trabalhadores. 
Os dados coletados na observação participante foram registrados em diário de campo e as entrevistas coletivas foram gravadas e transcritas na íntegra para efeito de análise. Uma vez transcritas, todas as entrevistas foram analisadas segundo dois temas centrais: saúde e trabalho e posteriormente foram subdivididos nas seguintes categorias:

- Sentido do trabalho

- Sentido da saúde

- Interface saúde-trabalho

- Condições de trabalho: pressões físicas, mecânicas, químicas e biológicas do posto de trabalho, incluindo riscos e prevenção de acidentes e doenças ocupacionais.

- Organização do trabalho: divisão de tarefas entre os trabalhadores, repartição, cadência, o modo operatório prescrito, repartição de responsabilidades, hierarquia, comando, controle, relações horizontais, representação sindical etc.

\section{Condições e organização do trabalho: a vivência dos trabalhadores}

\section{As Pedreiras}

Nas pedreiras ou empresas de extração, os trabalhadores se dividem nas funções de operador de martelete (marteleteiro), cabo de fogo (cabuqueiro), operador de fio diamantado (fiolista), manobreiro (manobrista), encarregado e supervisor.

Os marteleteiros são responsáveis pela limpeza da pedreira, retiram das rochas suas imperfeições para que o terreno, antes acidentado, seja transformado numa plataforma lisa ou "prancha". Em seguida, perfuram a "prancha" com o martelete para possibilitar a instalação das hastes do aparelho de fio diamantado - trata-se de um equipamento relativamente novo introduzido no setor e que realiza o corte da pedra - e auxiliam na extração dos blocos. Ao realizarem essa função, os trabalhadores estão sempre em contato direto com a poeira, o barulho e a trepidação que são emitidos pelo martelete.

O cabuqueiro é o operário responsável pela utilização de explosivos. É ele quem "detona" ou "dá fogo" na pedreira. Seu trabalho consiste em detonar explosivos na área trabalhada pelos marteleteiros para que se inicie o processo de extração dos blocos. É também sua tarefa explodir rochas e blocos que sejam desnecessários ao processo. Nessa função, o risco de morte e acidentes graves é permanente, pois o trabalhador lida diretamente com explosivos e com possíveis desmoronamentos de pedras.

Preparado o terreno, entram em campo os fiolistas, cuja função consiste em operar o equipamento de corte da rocha (fio diamantado). Cortada em algumas horas, forma-se um bloco de pedra isolado do restante da "prancha". Os fiolistas também convivem com o barulho, a poeira e principalmente com o risco de o fio diamantado quebrar e atingir violentamente seus corpos, devido à proximidade que ficam para realizar corretamente o corte.

Após essa operação, preparam o bloco que será deslocado do local de onde foi extraído. Os manobristas colocam a "malha" de aço no bloco, que será conectada ao cabo principal da "lança". A "lança" é um guincho capaz de suportar toneladas e içar blocos de granito ou mármore do local de extração até o local de armazenamento da empresa, de onde serão transportados para as serrarias, onde finalmente o bloco começará a ser beneficiado. 
Os manobristas são responsáveis pela operação chamada de "manobra", uma das mais arriscadas realizadas na pedreira devido à possibilidade de queda dos blocos içados pela lança ou pela ruptura dos cabos de aço, o que pode ocasionar acidentes graves envolvendo os trabalhadores. Os encarregados e supervisores inspecionam todas essas etapas da produção.

Paralelamente ao trabalho dos funcionários da pedreira existem algumas pessoas que trabalham sem vínculo empregatício com a empresa, que são chamados de trabalhadores de "pedra marruada". Esses trabalhadores ganham ou compram por pequenas quantias os blocos defeituosos retirados da pedreira. Explodem o bloco em partes menores e depois continuam quebrando as pedras manualmente com o "marrom", uma marreta pesada de aproximadamente 10 quilos. As pedras, depois de serem devidamente "marruadas", são transportadas por caminhões até as Moageiras, onde serão transformadas em pó de mármore.

Muitos trabalhadores dependem desta atividade com as "pedras marruadas" em Cachoeiro do Itapemirim para sobreviver. Vários deles perdem suas vidas ou têm partes do seu corpo amputadas pelas explosões, por não saberem trabalhar com explosivos, não possuírem os equipamentos adequados para essa operação.

De acordo com as normas de segurança exigidas nessa atividade, todas as empresas que lidam com explosivos deveriam ter no quadro de funcionários um trabalhador com curso específico para lidar com esse material. Pudemos constatar em outros relatos que essa norma não é obedecida e os trabalhadores mais experientes em "dar fogo" - detonação de explosivos - "ensinam" aqueles que ainda não sabem.

Quando há detonação de explosivos dentro da empresa ou nas empresas que se localizam nos arredores, os trabalhadores só podem se prevenir de acidentes tentando se esconder em algum local que supõem seguro ou, se não houver tempo para se esconderem devido ao desrespeito aos horários de detonação, devem ficar atentos para poderem se desviar da pedras que "voam".

Tem um monte de firma em volta, sem dizer a marruada, né - quem mexe com pedra quebrada - detona fogo toda hora... todos desrespeitam... detonam a hora que quer. Tem que saber prá onde que tá o fogo [explosão], se for prá lá a gente se esconde prá cá, tem que saber de onde é o fogo, senão a gente vai tá escondendo pro lado do fogo. Se não achar lugar de esconder tem que ficar olhando pra ver onde que cai... Porque se correr de costa é pior, vir uma pedra nas costas da gente, não tá vendo.

Nas pedreiras, os trabalhadores cumprem uma jornada de trabalho de 44 horas semanais, subdivididas em 9 horas por 4 dias na semana e 8 horas no último dia útil, com pausa de 1 hora para o almoço.

Devido às condições de trabalho específicas dessa atividade - na qual o risco de acidentes causados pelas explosões e das manobras é constante -, os trabalhadores necessitam manter um relacionamento entre eles em que a confiança e a amizade devem suplantar quaisquer divergências. $O$ ruído produzido pelos marteletes obriga o uso de protetores auriculares e abafadores que dificultam a percepção dos trabalhadores dos sinais de aviso de detonação, quando e se eles acontecem. Para que eles possam se proteger a tempo é necessário contar com o aviso dos demais companheiros de trabalho.

Na área do mármore, na pedreira aqui, companheiro de serviço não pode ter nenhum tipo de problema um com outro... Se o cara tiver em perigo e o outro não tá se dando com ele, não vai avisar. Alguma coisa tem que passar por cima daquilo, o cara hoje tá sem jeito com o outro, amanhã tem que tá tranqüilo, senão não funciona, tem que tá tudo bem, igual irmão mesmo. 


\section{Serrarias e Marmorarias}

$\mathrm{Na}$ serraria encontramos os trabalhadores designados para as funções de serradores, polidores e acabadores. Os blocos de mármore e granito provenientes da pedreira são transportados e colocados nos teares que "serram" o bloco durante aproximadamente 3 dias ininterruptos, desdobrando-o em chapas não polidas .

Os serradores precisam supervisionar o andamento da "serragem", dosar a alimentação das máquinas com água, areia, cal e granalha de aço - produtos auxiliares no processo de corte -, realizar manutenção nos teares e substituir as serras gastas, quando for necessário. Cumprem uma jornada de turnos alternados, revezando-se num sistema de 12 por 36 horas.

Relatam esses trabalhadores que a profissão se aprende na prática. Iniciam-se na profissão como ajudantes de serrador e podem chegar a encarregados do setor. Muitos nos contaram que, com o tempo de experiência, podem identificar qualquer falha no sistema somente pelo ruído ou pela vibração produzidos pelo tear, momento no qual precisam intervir.

O produto final da serragem, as chapas não polidas, podem ser vendidas para outras marmorarias ou podem ser transportadas para o pátio de estoque da própria marmoraria, caso esta também execute ações de beneficiamento.

A Marmoraria é a terceira etapa da industrialização do mineral granito ou mármore, também chamada de Beneficiamento. É constituída pelos setores de polimento, corte, acabamento e montagem.

O setor de polimento constitui-se num processo dos mais monótonos e repetitivos entre os que são executados na marmoraria, segundo os trabalhadores. Trabalhando isolados uns dos outros, cada polidor opera seu equipamento, chegando a polir cerca de 6 chapas de pedra por dia. Muitos trabalhadores relataram que ao longo do dia sentem muito sono, momento em que, quando possível, interrompem o trabalho por alguns minutos para tentar "espantar o sono".

Essa tarefa envolve risco de acidentes durante a remoção, substituição e transporte das chapas polidas, assim como determina um trabalho conjunto dos polidores do setor nessa fase da tarefa. Esse transporte de chapas é bastante perigoso, pois as chapas podem se partir e cair sobre os trabalhadores.

Depois de polidas, as chapas poderão ser vendidas para outras empresas ou seguirão para o setor de corte e acabamento para a fabricação de produtos voltados para a construção civil - pias, soleiras, bancadas. Durante essa etapa da produção os trabalhadores estão em contato direto com o pó proveniente do corte e do lixamento das chapas de mármore e granito.

\section{Moageiras}

A moageira se divide em vários setores: britagem, ensaque, estoque e expedição, manutenção, laboratório. São empresas que transformam pedras "marruadas" de mármore em diversos tipos de pó com espessura, qualidade e utilidade diferentes. Os vários tipos de pó produzidos pelas moageiras podem ser empregados nas indústrias de argamassas, asfalto, azulejo, amianto, borrachas, chicletes, cosméticos, colas, eletrodos, papéis, produtos farmacêuticos, produtos de limpeza, siderurgia, tapetes, vidros, tintas e rações.

Os britadores são responsáveis pelo trabalho de limpeza e seleção das pedras de má qualidade. Esses trabalhadores convivem diariamente com o barulho, o pó e o risco de serem atingidos por pedras quando caminhões as descarregam no britador. 
As pedras são transportadas através de correias em sucessivos britadores, onde vão sendo trituradas em tamanhos cada vez menores e continuam seguindo pela esteira até chegarem nos locais de estoque. Do local de estoque, as "britas" continuam sendo encaminhadas pelas correias e divididas em silos onde são moídas ainda mais, transformandose em pós de características e finalidades diferentes.

Os ensacadores empacotam o pó em sacos de 50 quilos e trabalham em turnos alternados cumprindo uma jornada de trabalho de oito horas diárias com pausa de uma hora para a refeição.

Entre os ensacadores e carregadores, as queixas relativas aos problemas de coluna causados pelo peso foram justificadas também em função do ritmo de produção. Segundo alguns trabalhadores, há um modo "certo" para carregar os sacos que evita ou ameniza os efeitos dessa atividade; porém, se assim o fizerem, perdem muito tempo e não dão conta da tarefa que deve ser executada no dia. Os trabalhadores do setor de estoque e expedição realizam o transporte dos sacos de pó de mármore dentro da fábrica, utilizando-se de empilhadeiras, organizando ou carregando manualmente esses sacos para as carretas.

Paralelamente a esses setores, existem os trabalhadores do setor de manutenção, que instalam, substituem e consertam os equipamentos da empresa e os trabalhadores do laboratório, que são responsáveis pela coleta de amostras do pó para realizarem exames que atestam sua qualidade final.

Verificamos, entre os trabalhadores dessa empresa, enunciações que expressavam um sentimento de orgulho, tanto por trabalharem com um produto que está presente na fabricação de muitos e variados produtos industrializados, como também por pertencerem ao quadro de uma das empresas que parece se constituir, na comunidade local, como uma das melhores e mais importantes da região.

Este é um relato sucinto das condições e organização do trabalho vivenciadas pelos trabalhadores. A partir destas e outras discussões, após a transcrição de todas as fitas de entrevistas gravadas com trabalhadores, utilizamos a análise do discurso como possibilidade de investigar o sentido que os trabalhadores atribuem à atividade que realizam no cotidiano. Entendendo que a produção de sentidos se dá através do discurso, este, antes de ser uma atividade cognitiva intraindividual, constitui-se como uma produção social, um empreendimento coletivo por meio do qual as pessoas compreendem e lidam com as situações e fenômenos à sua volta.

Tal como aponta Spink (1999), as práticas discursivas, definidas como linguagem em ação, é a maneira pela qual as pessoas produzem sentidos e se posicionam nas suas relações sociais cotidianas, uma vez que o uso da linguagem sustenta as práticas sociais.

Partindo-se dessa perspectiva de análise, consideramos o contexto sócio-histórico, político e cultural, os interlocutores presentes ou presentificados, o espaço e o tempo como fatores que moldam uma forma de discurso, ou seja, como certas prescrições lingüísticas, regras e valores orientam as práticas cotidianas das pessoas.

Ao mesmo tempo, além de suas regularidades, o discurso também comporta a dimensão da diversidade e da não-regularidade presentes em diferentes contextos em que ele é produzido e de acordo com os repertórios interpretativos ${ }^{27}$ de que se dispõe. Estes

\footnotetext{
${ }^{27}$ Repertórios interpretativos são as unidades de construção de práticas discursivas ou o conjunto de termos, descrições, lugares-comuns e figuras de linguagem que demarcam o rol de possibilidades de construções discursivas, tendo por parâmetros o contexto em que essas práticas são produzidas e os estilos gramaticais específicos.
} 
produzirão diferentes sentidos que, por sua vez, irão gerar diversas ações, interações e práticas sociais. Tudo isso cotejado junto às observações registradas em nossos diários de campo e nossas próprias vivências nos locais de trabalho.

Desta forma, elegemos aprofundar nosso trabalho em três categorias: a noção de Saúde, a de Trabalho e a Interface Saúde-Trabalho. O aprofundamento nessas questões nos aponta para a enormidade de outras que não foram aqui problematizadas. Trata-se, sem dúvida, de um setor ainda inexplorado do ponto de vista do estudo do processo de saúde e trabalho e não temos aqui a pretensão de esgotar o assunto. Pelo contrário, apontamos para a necessidade da continuação e aprofundamento de estudos neste setor, devido não somente ao quadro atual de precariedade do conhecimento no campo, como também quanto à quantidade e qualidade dos agravos à saúde que esse tipo de processo de trabalho acarreta. Agravos que atingem não somente aos trabalhadores que ali labutam, como também a toda população do entorno e, ainda, com conseqüências nefastas ao meio ambiente.

\section{Produzindo sentidos: saúde, trabalho e a interface trabalho-saúde}

\section{A noção de saúde}

Ao iniciarmos nosso trabalho de campo, tínhamos clareza em relação aos efeitos perversos à saúde que tal trabalho provocava nos trabalhadores. Qual não foi nossa surpresa quando essa relação não era evidenciada de maneira tão explícita pelos trabalhadores. Eles tinham, sim, a noção de que o trabalho poderia afetar a saúde - MAS no futuro: quem sabe um probleminha de ouvido, um probleminha de coluna, alguma coisinha no pulmão...

Aproximarmo-nos dos sentidos atribuídos por esses trabalhadores aos termos "trabalho" e "saúde", ao lado das nossas experiências em situações no campo, foram se constituindo como a principal via de acesso na compreensão das vivências subjetivas daqueles sujeitos. Nossa implicação nessa pesquisa não dizia respeito somente de uma relação que se pretende neutra entre sujeito e objeto a ser conhecido.

Ao contrário, levávamos a campo nossos próprios valores, conceitos, visões de mundo e de homem, que foram sendo confrontados com uma outra realidade. Desse confronto de idéias e de subjetividades, mediados pela linguagem, é que pudemos, junto com os trabalhadores, questionar como e/ou sobre quais práticas e discursos, socialmente construídos, a realidade do mundo do trabalho atual se sustenta e tentar nos aproximar de alguns caminhos que nos levariam a compreender os processos subjetivos mobilizados pelos trabalhadores para o enfrentamento daquela realidade.

Neste sentido, a primeira providência foi problematizar a noção de saúde: do que é que estávamos (pesquisadores e trabalhadores) falando, afinal?

Entendemos a saúde enquanto um processo social e, acompanhando Dejours (1993), entendemos que:

o trabalho é um dado fundamental da saúde. Não somente de maneira negativa (trabalho como causa de doenças, de intoxicações, de acidentes, de desgastes etc.), mas também de forma positiva. O não-trabalho também pode ser perigoso para a saúde, como se vê bem, atualmente, com toda a patologia do desemprego. (p. 101) 
Entendemos o trabalho como fato social determinante no processo saúde-doença. Do nosso ponto de vista, era por demais evidente a associação entre aquele tipo de trabalho e agravos à saúde.

No entanto, pudemos compreender que aquela população entende a saúde como a própria condição de trabalho. Saúde é tudo, sem saúde não se trabalha, não se vive.

Nas falas dos entrevistados, as noções de saúde e doença parecem fazer sentido se vinculados ao trabalho, já que a doença vai se caracterizar como um impedimento ao trabalho. Vejamos as descrições dos próprios trabalhadores:

Saúde é tudo.

Sem saúde nós não é nada.

Eu penso que quem não tem saúde sente, sente cansaço, sente dor, desânimo, é infeliz.

Saúde é não ter nada, nenhuma doença, estar bem e trabalhando.

Tal como aponta Minayo (1994):

As expressões correntes: a saúde é tudo, é a maior riqueza, saúde é igual a fortuna, é o maior tesouro; em oposição a doença como castigo, infelicidade, miséria etc. são representações eloqüentes de uma realidade onde o corpo se tornou, para a maioria, o único gerador de bens. (Minayo, 1994, citado por Nardi, 1998, p. 98)

Foi possível observar que nas atividades desenvolvidas nesse setor o predomínio do componente físico ${ }^{2}$ na execução do trabalho produz nos trabalhadores uma noção de saúde onde a "força" e a "disposição" do corpo para o trabalho, parecem ser os principais fatores que dizem de um corpo saudável. Ter saúde é "ter força" e "ter disposição", sendo assim, o sentido de saúde é concretizado no corpo. Ter ou não ter saúde é um estado visível que se reflete no corpo, tal como ilustra esse segmento do discurso de um trabalhador:

[saúde] É tudo sim... que tem até um dizer assim: que a vida é dura para quem é mole. E quem não tem saúde é onde dá moleza; a vida é dura para quem é mole e quem tem saúde não tem nada de moleza não.

Nesse segmento, o entrevistado fala do que é não ter saúde, relacionando a esse estado de "moleza". Boltanski (1979), em As classes sociais e o corpo, aponta que:

A valorização da atividade física e da força física, que é correlativa de um uso instrumental do corpo, fazem com que a doença seja sentida primeiro como um entrave à atividade física e ocasione essencialmente um sentimento de fraqueza. (...) A doença é o que tira a força do doente, ou seja, o que o impede de 'viver normalmente' e fazer de seu corpo um uso (profissional principalmente) habitual e familiar. (p. 161)

Uma das condições de trabalho presente em todas as empresas visitadas refere-se à exposição dos trabalhadores a um alto nível de ruído. Diversos estudos apontam para os efeitos nocivos à saúde provocados pela poluição sonora no ambiente de trabalho. Pudemos

\footnotetext{
2 De acordo com a Ergonomia, esse componente relaciona-se aos gestos, às posturas e aos deslocamentos do trabalhador, necessários à execução da tarefa. A quantidade de esforço físico despendido por cada trabalhador na realização da tarefa expressa a carga física da jornada de trabalho.
} 
observar nas falas dos entrevistados referências a problemas de saúde já existentes relacionados à audição.

O exame, por exemplo, que a gente fez, eu fiz antes de ontem, a doutora disse que tinha um problemazinho assim, mas a gente, assim, não sente diferença alguma.

Meu exame de ouvido deu problema... uma coisinha à toa, não é nada não.

Fica aquele barulhinho enjoado um tempo. Às vezes, até no outro dia, quando a gente vem trabalhar de novo, ainda tem o barulhinho.

Pode-se perceber nessas falas, no entanto, que para esses trabalhadores, embora tenha sido identificada, via exames periódicos, a existência de problemas auditivos, esses parecem não se constituir como uma verdadeira doença ou agravo a saúde, uma vez que o corpo se mantém apto para o trabalho, confirmando, dessa forma, que o sentido de saúde está diretamente relacionado ao impedimento ou não do corpo ao trabalho diário.

Muitos trabalhadores demonstraram ter conhecimento de que os efeitos nocivos à saúde que as condições de trabalho produzem sobre o corpo podem se intensificar e que, com o tempo, podem se agravar. Ao vincular o sentido da saúde ao trabalho, porém, esses agravos são minimizados ou se constituem como um mal com o qual, fatalmente, terão que se haver no futuro, pois no presente ainda não os impedem de executar suas tarefas cotidianas.

... é como um vício, a gente sabe que vai fazer mal mais tarde, mas o vício a gente pode largar, já o trabalho não, é uma obrigação.

É, isso aí [problemas de saúde decorrentes das condições de trabalho] no futuro a gente pode pensar...

Boltanski (1979), ao apresentar um estudo comparativo das necessidades médicas entre as classes sociais, assinala que, para os membros das classes populares que usam o corpo como instrumento de trabalho e subordinando sua utilização tão somente às funções sociais, a doença pode manifestar-se brutalmente, quer porque eles não se aperceberam, quer porque se recusaram a perceber os sinais precoces.

O caráter insidioso das doenças que os acometem parece ser um dado que não se vincula ao sentido de saúde desses trabalhadores, seja porque dentro do contexto em que eles se encontram é suficiente ter um "corpo que funcione para o trabalho", como também, como expressaram esses mesmos trabalhadores, a precariedade de acesso ao serviço público de saúde os impede de realizar um tratamento adequado .

Esquece esse negócio de médico, até porque a dificuldade hoje de você conseguir um médico... você tem que pagar tudo, então é melhor, se você sentir alguma coisa, você tomar um chá, tomar alguma coisa. Se você for no hospital, você não agüenta pagar. Se você chegar lá na Santa Casa com dois mil real, três mil real no bolso e falar com o médico: 'eu quero um checkup de tudo'. O médico vai saber tudo o que eu tenho. Rapidinho eles fazem tudo e te dão o resultado ali ó, perfeito... Do contrário, você não tem nada... todos os hospitais funcionam assim, não adianta, se tiver dinheiro é bem tratado, se não tiver...

Essa noção de saúde apontada pelos trabalhadores pode ser melhor compreendida quando nos dispusemos a investigar qual é o sentido do trabalho para esta população. 


\section{A noção de trabalho}

Não é possível discutir o trabalho sem pensá-lo enquanto um fenômeno histórico, produto de transformações em função das diversas e diferentes práticas e contextos que propiciaram o seu surgimento. A noção de trabalho se constrói a partir de todo um conjunto de configurações históricas, sociais e políticas específicas que não necessariamente são as mesmas em todo tempo e em todo espaço (Gondar, 1989).

Para ilustrar tal fato, podemos lembrar a antiga sociedade grega, na qual a categoria trabalho sequer existia. As atividades de profissão não possuíam valor social a não ser como expressão de talentos variados. A sociedade política, longe de ser referendada pelo valor da atividade de profissão, tinha como referência a lei e a idéia de igualdade entre os homens livres. A estes estava reservada a dignidade da atividade do pensar, ficando as atividades manuais desvalorizadas, destinadas apenas aos escravos.

Já durante a Idade Média, principalmente com o advento do Cristianismo e a instauração da ordem monástica, o trabalho se atrela a um valor moral, enquanto uma possibilidade de domínio do espírito sobre o corpo.

Era necessário viabilizar um tipo de atividade que pudesse enfraquecer ainda mais a carne, de maneira que ela não pudesse se fazer valer através da memória. Esta atividade é o trabalho, aqui concebido como dispêndio de energia, ou seja, como modo de ocupar o corpo até a exaustão, eliminando nele qualquer indício do desejo e de sua força. (Gondar, 1989, p. 28)

Com os monastérios, outros valores também começaram a tomar forma junto à idéia de trabalho. A disciplina e a necessidade de se dividir o tempo em horários e intervalos são heranças das ordens monásticas que acabaram por se consolidar nos anos que se seguiram.

Pouco a pouco o trabalho foi perdendo o caráter de sacrifício e ganhando uma dimensão de produção, essencial à condição humana. A ascensão da burguesia e a necessidade de construção das cidades durante a Idade Moderna trouxeram uma nova configuração da realidade, baseada na necessidade de acumulação de capital, de ampliação dos mercados, de aperfeiçoamento de técnicas e incremento na produção.

Com as fábricas, o até então pequeno artesão de produção doméstica e familiar é expropriado de seu saber-fazer, perdendo o controle do processo de trabalho e vendo-se obrigado a vender sua força sob a forma de mão-de-obra. $O$ fruto do trabalho deixa de ser do trabalhador e o progresso industrial é construído às custas da exploração.

Para atender aos interesses burgueses, o trabalho adquire valor de troca e a mercadoria passa a ter maior importância do que o próprio homem. Forja-se assim a instauração do trabalho enquanto necessidade, dando sentido à própria vida.

Tal noção que coloca o trabalho como entidade absoluta, encontra forte ressonância em nossos tempos atuais. Concebe-se o trabalho como algo "natural" ao homem, componente de sua "essência", esquecendo-se de problematizar seu valor histórico.

Uma das principais conseqüências de tal forma de pensar pode ser verificada quando nos deparamos com o atual quadro de desemprego e da falta de perspectiva de empregos. Por não ser possível mais separar o homem do trabalho, recai sobre o homem sem trabalho, ou melhor, sem emprego, toda a carga de culpa, vergonha e resignação. Se for verdade que o trabalho organiza a vida, uma vida sem o trabalho acaba por ser considerada de pouco valor (ou mesmo sem valor!), aproximando o homem da inutilidade (Forrester, 1997).

A partir dos encontros que pudemos ter com os trabalhadores do mármore e do granito, não nos restou dúvida em relação ao lugar privilegiado que o trabalho ocupa em suas vidas. Foi-nos possível ouvir e pensar sobre os diversos sentidos atribuídos por eles ao 
trabalho. De tudo o que foi enunciado, no entanto, pareceu-nos mais marcante as falas que remetem a três sentidos específicos do trabalho, três faces em que o trabalho se apresenta em suas vidas.

\section{Trabalho como sobrevivência}

Trabalhar, a gente tem que trabalhar mesmo. Ou ali, ou aqui, de um jeito ou de outro, a gente, se não trabalha, não tem 'papa'... Prá sobreviver. Precisa sustentar a gente, a si mesmo e à família...

Uma das enunciações muito presentes entre os trabalhadores remete à idéia de trabalho enquanto um modo de sustentar a família, uma garantia de sobrevivência. Trabalhar parece assumir um valor de obrigação, um "fardo pesado" que permite apenas "sobreviver" diante da realidade, uma forma, talvez a única, de se sentir vivo e presente. Seja qual for o trabalho, em quaisquer condições, trabalhar representaria a garantia de vida e de dignidade. Nesse sentido, "é necessário trabalhar", ainda que a vida e a saúde sejam colocadas em risco pelas condições e pela organização do trabalho.

\section{Trabalho como atividade natural do homem}

... o trabalho faz parte da vida do homem, não tem prá onde o homem correr. Mesmo se ele tiver dinheiro, ele vai ter que trabalhar, de um jeito ou de outro, ele vai ter que trabalhar. Isso aí faz parte, o homem já nasceu prá isso, trabalhar...

Em outros momentos foi possível percebermos também muito presente a idéia de trabalho enquanto uma atividade inerente ao homem, algo que o define e que sem o qual o homem não se faz homem. Mesmo que as condições de sobrevivência já sejam dadas, "trabalhar é necessário" para que se possa se assumir enquanto homem.

Tal concepção, se por um lado reforça a idéia de trabalho enquanto essência humana, enquanto o que "enobrece o homem", por outro lado pode estar remetendo a um discurso que tenta legitimar a necessidade de afirmação do lugar social do masculino enquanto provedor, o responsável pelo sustento da família e da prole. Estas duas análises possíveis dão uma dimensão do quanto o sentido do trabalho está atravessado por diversos valores morais e subjetivos construídos social e historicamente. É como se do homem fosse exigido a todo tempo a manifestação da masculinidade através da força do trabalho e do fomento financeiro da família, confirmando assim o pátrio poder expresso na figura do "chefe da casa". "A capacidade e as habilidades para o trabalho - em especial, aquele duro e pesado - são elementos constituintes importantes do 'ethos masculino' nas classes trabalhadoras" (Nardi, 1998, p. 95).

Trabalhar pode ser natural ao homem, também, por estar associado à idéia de atividade, de produtividade e, por conseguinte, de utilidade. Há um desejo grande por ser útil, por fazer algo, por não se caracterizar pelo ócio, ainda que seja um descanso. Até mesmo a aposentadoria é vista com certa desconfiança.

Se aposentar, morre...

Eu não paro. Nunca tirei férias aqui... Então prá que eu vou parar de trabalhar? Nós, trabalhadores, se parar de trabalhar, morre...

O trabalho, aqui, adquire importância maior do que qualquer outra dimensão da vida (sem trabalho não há vida) e, por isso, torna-se referência estruturante da própria existência. 


\section{Trabalho como espaço social}

... [o trabalho] distrai também... Eu não consigo ficar em casa...

... tem amigos, tem o diálogo, né... Amizade, consideração. Porque o homem não vive só. Um precisa do outro...

Muitas vezes, a gente aqui, em grupo, consegue falar coisas que a gente deveria falar com os patrões e a gente não fala. E aqui a gente consegue falar...

Um outro sentido atribuído ao trabalho enunciado pelos trabalhadores, diz respeito à idéia do trabalho enquanto um lugar onde se constróem e se fortalecem laços afetivos de companheirismo e amizade. Entendem que o trabalho permite trocas com outras pessoas, permite compartilhar as vivências, os conflitos, as angústias e permite também vislumbrar formas alternativas de solucionar problemas e de lidar com a realidade.

Seja através das conversas informais nos intervalos da jornada de trabalho, seja na realização de tarefas em grupo, ou mesmo nos momentos de lazer vivenciados em comum, percebe-se que os vínculos subjetivos são criados, tornando-se fundamentais para a produção coletiva de sentidos do cotidiano. $O$ trabalho, assim, assume um valor enquanto prática social que faz com que o sujeito se sinta participante e também responsável pela transformação da realidade.

Trabalho aqui adquire o sentido de produção; não a produção de lucro capitalista, mas a produção coletiva de sentido e de realidade, o que só é possível a partir do envolvimento dos sujeitos em uma rede solidária de afetos produtores de dignidade.

\section{Interface trabalho-saúde}

Aqui podemos pensar a interface trabalho-saúde. $O$ trabalho torna-se um "bem" tão importante ou mais até do que a própria saúde. Trabalho aqui é meio de sobreviver, faz parte da "natureza" humana, principalmente a do homem, e ainda possibilita um certo tipo de sociabilidade. Como não trabalhar? Como dar uma pausa ao trabalho para cuidar de algum "probleminha" de saúde? De uma só vez perde-se o meio de sobrevivência, perde-se até mesmo a dignidade enquanto ser humano e ainda perde-se as amizades, as brincadeiras, o cotidiano construído junto com colegas de trabalho. Se estou cansado, se minha jornada terminou, mas ainda temos um bloco para serrar, o que fazer? Parar? E se o patrão achar que estou "sendo exigente"? Coloco em risco meu emprego? Minha coluna já está doendo, mas fazer o quê? Assim, os trabalhadores extrapolam os limites que o próprio corpo denuncia: a maioria dos trabalhadores conhece e explicita as possibilidades de agravo à saúde, mas o trabalho, com toda a carga de sentido que já discutimos acima, torna-se moeda muito mais forte do que a saúde.

Aqui temos a possibilidade de compreender porque os riscos deste tipo de trabalho são, por vezes, minimizados pelos trabalhadores. Não se trata de descuido ou falta de educação (como é constantemente veiculado), mas simplesmente:

Se a gente ficar pensando muito nisso aí, não dá prá trabalhar. (trabalhador de pedreira)

A real dimensão dos perigos a que estão submetidos pode inviabilizar o retorno ao trabalho no dia seguinte. Minimizar os riscos, juntamente com a grande valorização da atividade de trabalho pode ser o modo que estes trabalhadores encontram para suportar o cotidiano penoso e perigoso. Como dizem os trabalhadores, o resto (o perigo, o futuro, as conseqüências para a saúde, tudo aquilo que eles imaginam não ter ingerência ou controle) entrega-se para Deus. 
Aqui temos a possibilidade de compreender também porque muitas vezes os trabalhadores recusam os EPIs: em primeiro lugar, a execução do trabalho está acima de qualquer coisa. Muitos dos EPIs causam desconforto aos trabalhadores; aqui o zelo pelo trabalho fala mais alto do que a própria proteção à saúde. Com todos estes equipamentos, tenho que trabalhar mais devagar, não enxergo direito, não respiro direito. Será que o patrão está disposto a diminuir o ritmo de produção? Em segundo lugar os trabalhadores, embora nem sempre enunciem, têm clareza dos limites da proteção oferecida pelos EPIs. Contra pedras voadoras, ainda não inventaram um capacete bom o suficiente. $\mathrm{O}$ ruído constante nem sempre consegue evitar a surdez ou evitar

um enxame de abelhas dentro da cabeça...

...que faz os nervos pularem na hora de dormir.

Enfim, trata-se de uma discussão bastante complexa, que não conseguiremos esgotar aqui. Apenas evidenciar os limites dos equipamentos em relação à saúde e segurança dos trabalhadores e evidenciar, ainda, o fato de que os trabalhadores, melhor do que ninguém, sabem disso.

Os trabalhadores contam com outros elementos que não os EPIs para se protegerem dos perigos. Um destes elementos, importantíssimo, diz respeito à amizade entre eles. Por diversas vezes fomos alertados para o fato de que num setor tão perigoso não pode haver inimizades. As "diferenças" devem ser resolvidas, pois os trabalhadores dependem da solidariedade do companheiro para avisá-los sobre detonações, perigos não percebidos e até mesmo para socorrê-los, se necessário. Numa pedreira, um trabalhador surdo conseguia perceber detonações tanto pela vibração provocada na pedra, como também pelo alerta e aviso dos companheiros de trabalho.

Empresários, sindicalistas e trabalhadores buscam, cada um a seu modo, soluções para o perigo para a saúde e a vida que este tipo de trabalho acarreta. No entanto, tivemos a oportunidade de observar que as discussões e o planejamento de atividades relacionadas à saúde não levam em conta, em nenhum momento, a efetiva participação do trabalhador. Menos ainda se cogita na transformação, não das atitudes do trabalhador, mas da própria organização do trabalho.

Esta pesquisa no setor de rochas ornamentais reafirmou para nós o compromisso ético que norteou nosso trabalho. É impossível pesquisar, planejar práticas com trabalhadores no campo da saúde e segurança, sem levar em conta o sentido que o trabalho e a saúde assume para estes trabalhadores, sem conhecer seu cotidiano de trabalho, sem compartilhar as artimanhas construídas no dia-a-dia para dar conta da realidade.

Nossa pesquisa nos mostrou com muita clareza a importância de se ouvir o discurso do trabalhador com estatuto de verdade, conhecer sua realidade a partir de sua própria vivência. Esse é, a nosso ver, o viés que deve estar subjacente às práticas de saúde no trabalho, tanto no sentido de formação e informação de trabalhadores, quanto na ética de pesquisa ensinada para alunos de graduação na investigação dos problemas aqui levantados.

Stone Men? Researching the work and health process in the marble extraction and processing - writing about an experience

The marble extraction and processing is an important economical activity in Espirito Santo. Studies show the bad conditions in which this work is performed causing a high number of accidents and constant damage to the health of workers. In this study, we aimed to know, besides the working conditions, more about the work organization, in order to evaluate the produced effects on the workers' subjectivity. The research was based on the methodological 
strategies of the Situated Ergonomics and Work Psychodynamics. As data collector tools, we used both the participant observation and individual and collective interviews with workers. We also used the speech analysis in order to get closer to the meanings workers give to work, health and their interface. We understand health as a process and work as an important social fact towards the health and subjectivity of the workers. Health is an extremely important fact for the workers because being healthy is having a body ready to work. The consequences of the occupational diseases didn't prevent workers from performing their regular tasks. The concern with health was projected to an uncertain future, when the illness would have already become a reality, therefore, preventing them from working. This idea allowed workers to bear the hard work routine, but it also discouraged more effective actions as far as health and safety precautions at work.

Keywords: Work, Marble, Granite, Health, Subjectivity.

Endereço para contato com os autores:

Maria das Graças Barbosa Moulin: mariamoulin@uol.com.br

Cleison Teobaldo dos Reis: cleisoncarlareis@bol.com.br

Grace Hitomi Wenichi: ghwenichi@bol.com.br

Manuscrito recebido em: 25/04/01

Aprovado para publicação em: 04/10/01

\section{Referências}

Antunes, R. (1997). Trabalho, reestruturação produtiva e algumas repercussões no sindicalismo brasileiro. In R. Antunes (Org.), Neoliberalismo, trabalho e sindicatos: reestruturação produtiva no Brasil e na Inglaterra (pp. 71-84). São Paulo: Jinkings Editores Associados Ltda.

Becker, H. S. (1997). Métodos de pesquisa em ciências sociais (3 ${ }^{\mathrm{a}}$ ed.). São Paulo: Hucitec.

Boltanski, L. (1979). As classes sociais e o corpo. Rio de Janeiro: Graal.

Dejours, C. (1993, maio/junho). Por um trabalho, fator de equilíbrio. Revista de Administração de Empresas, São Paulo, 33, 98-104.

Dejours, C., Abdoucheli, E. \& Jayet, C. (1994). Psicodinâmica do Trabalho. São Paulo: Atlas.

Forrester, V. (1997). O horror econômico. São Paulo: UNESP Editora.

Gondar, J. de O. (1989, janeiro/junho). O trabalho como objeto histórico. Cadernos do NUPSO, Rio de Janeiro, 2 (3), 20-32.

Nardi, H. C. (1998). O ethos masculino e o adoecimento relacionado ao trabalho. In L. F. D. Duarte \& O. F. Leal (Orgs.), Doença, sofrimento, perturbação: perspectivas etnográficas (pp. 95 104). Rio de Janeiro: Fiocruz.

Spink, M. J. P. (Org.) (1999). Práticas Discursivas e Produção de sentidos no Cotidiano: aproximações teóricas e metodológicas. São Paulo: Cortez-Editora. 